\title{
Current Status of Biomarker Discovery in Human clear Cell Renal Cell Carcinoma
}

\author{
Simon J. Cooper ${ }^{1 *}$, Han W. Tun ${ }^{2}$, Stephen M. Roper ${ }^{3}$, Yunee Kim, Thomas Kislinger ${ }^{4}$, Richard R. Drake ${ }^{3}$ and John A. Copland ${ }^{1}$ \\ ${ }^{1}$ Department of Cancer Biology, Mayo Clinic Comprehensive Cancer Center \\ ${ }^{2}$ Division of Hematology/Oncology, Internal Medicine Department, 4500 San Pablo Road, Mayo Clinic, Jacksonville, Florida, 32224 , USA \\ ${ }^{3}$ MUSC Proteomics Center and the Department of Molecular and Cellular Pharmacology and Experimental Therapeutics, Medical University of South Carolina, \\ Charleston, SC, 29425, USA \\ ${ }^{4}$ Department of Medical Biophysics and Ontario Cancer Institute, University of Toronto, Ontario M5G 1L7, Canada
}

\begin{abstract}
The incidence of clear cell renal cell carcinoma ( $c$ RCC) continues to increase while very few treatment options are available for therapy. Development of metastatic disease dramatically decreases patient survival; therefore detection at an early stage while still localized to the renal capsule is imperative for a favorable prognosis. With recent advances in molecular technologies and subsequent understanding of the underlying pathology of disease, molecular markers have been defined that are predicative of tumor stage, metastatic potential and patient prognosis. Analysis of these biomarkers along with current staging techniques already used in the clinic may allow for implementation of personalized post-surgical treatment plans as well provide further molecular pathways for targeted therapeutic interventions. In this review we will highlight the potential $\mathrm{cCRCC}$ biomarkers that have been identified through a variety of molecular techniques to date, and provide insight into research models for biomarker discovery.
\end{abstract}

Keywords: Clear Cell Renal Cell Carcinoma (ccRCC); Proteomics; Biomarkers; Gene Profiling; microRNA

\section{Introduction}

Renal cell carcinoma (RCC) is the third most prevalent urological cancer, the 10th most common cause of cancer death in men and the 9 th most common cause in women. Within this year more than 54,000 individuals will be diagnosed with RCC and around 12,000 will die from this disease [1]. Commonly asymptomatic, a third of RCCs are diagnosed when they are already metastatic resulting in a $95 \%$ mortality rate [2].

There are four major subtypes of RCC, papillary, chromophobe, collecting duct and clear cell, all of which originate from the renal tubular epithelium. Clear cell renal cell carcinoma (ccRCC) accounts for approximately $80 \%$ of all renal cancers and is therefore the most common subtype. Standard of care for the treatment of patients presenting with localized ccRCC is radical or partial nephrectomy, however $\sim 30 \%$ of these patients develop metastatic ccRCC even after surgery [3]. Metastatic tumors are usually identified in subsequent follow-up visits, post-surgery using imaging techniques that detect the mass of the established metastatic tumor. Traditionally metastatic ccRCC is chemo- and radiation-resistant providing literally no treatment options (cytokine therapy is beneficial in $<5 \%$ patients) other than surgical [4]. The development of metastatic ccRCC greatly reduces the 5-year survival of ccRCC patients to less than 10\% [5]. Therefore, early detection of ccRCC is of utmost importance for treatment and patient survival [2].

With the more common use of imaging procedures in the clinic, ccRCC and other masses within the kidney are being more readily identified and at an earlier stage. However, as these images cannot determine tumor stage, the best predictor of stage progression still remains tumor staging of postoperative tissue. As this staging process requires the patient to undergo surgery, the need for the identification of biomarkers capable of determining RCC type, tumor stage and metastatic potential that are obtainable from non-invasive or minimally invasive techniques / biological fluids (i.e. serum or urine) are desirable. However, biomarkers for early detection of ccRCC or metastatic disease potential do not currently exist resulting in late diagnosis and subsequent poor prognosis for patients with metastatic disease [6]. This is in spite of the relatively high availability of tissue, blood and urine samples compared to other human cancers that could be used to identify diagnostic and prognostic biomarkers of ccRCC.

The NIH defines a biomarker as "a characteristic that is objectively measured and evaluated as an indicator of normal biological processes, pathogenic processes, or pharmacological response to a therapeutic intervention." [7]. This review will focus on potential biomarkers in clear cell renal cell carcinoma that classify stage of disease, metastatic potential and patient outcomes as identified through immunohistochemistry, gene profiling, proteomics, microRNA and cytogenetic signatures. These biological markers of disease also have the potential to be novel therapeutic targets for drug development in a disease with few treatment options.

\section{von Hippel-Lindau (VHL) as a biomarker of ccRCC}

As cancer is a multifaceted disease leading to multiple changes in the genetic make up of patients, extensive research has been undertaken to identify underlying mutations and those genes that are epigenetically silenced in ccRCC patient tissue. The most documented mutation in ccRCC is in the tumor suppressor gene, von Hippel-Lindau (VHL) which has been reported to occur in $\sim 50 \%$ of all sporadic ccRCCs

*Corresponding author: Simon J. Cooper, Department of Cancer Biology, Mayo Clinic Comprehensive Cancer Center, 4500 San Pablo Road, Jacksonville, Florida, 32224, USA, Tel: +904-953-6045; Fax: +904-953-0277; E-mail: cooper.simon@ mayo.edu

Received September 20, 2011; Accepted December 15, 2011; Published January 05, 2012

Citation: Cooper SJ, Tun HW, Roper SM, Kim Y, Kislinger T, et al. (2012) Current Status of Biomarker Discovery in Human clear Cell Renal Cell Carcinoma. J Mol Biomark Diagn S2:005. doi:10.4172/2155-9929.S2-005

Copyright: (c) 2012 Cooper SJ, et al. This is an open-access article distributed under the terms of the Creative Commons Attribution License, which permits unrestricted use, distribution, and reproduction in any medium, provided the original author and source are credited 
[8]. Further silencing of the promoter of the VHL promoter through epigenetic changes has been reported in a further $10-20 \%$ of ccRCC [9].

The protein product of the VHL gene interacts with hypoxiainducible factors (HIFs) leading to HIFs subsequent ubiquitination and proteosomal degradation. Loss of VHL and subsequent HIFa accumulation leads to expression of transforming growth factor alpha causing activation of the signaling cascade epidermal growth factor

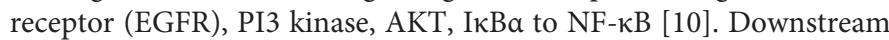
targets of the HIF signaling pathways are involved in cell survival, proliferation and angiogenesis [11]. The identification of these signaling cascades has brought about a number of targeted therapies that are approved for the treatment of RCC. Sunitinib, Sorafenib and Pazopanib which target receptor tyrosine kinases including VEGFR and Temsirolimus targets the mammalian target of rapamycin (mTOR). However these new targeted therapies are not able to cure ccRCC and their benefits to patient survival is only a number of months [12]

Studies examining VHL mutations as a predictor of prognosis for ccRCC have been inconsistent. Two large studies have identified that somatic VHL gene alterations lead to improved survival especially in early stage (stage1-2) disease $[13,14]$ but others state that mutations that lead to loss of function of VHL are associated with a poorer prognosis [15] and decreased overall survival [16].

\section{Gene Expression Profiling}

Gene profiling techniques have been used extensively in distinguishing transcriptional changes in patients with ccRCC compared to normal kidney tissue. Gene expression profiles have been created to distinguish RCC subtypes, gene signatures for early stage ccRCC and to define progression and metastatic potential of tumors. Studies comparing ccRCC, chromophobe and oncocytoma subtypes of RCC identified expression profiles for each of these subtypes of RCC that correlated strongly with histopathological classification. In these studies vimentin expression was identified to be a sensitive and specific marker for ccRCC [17]. Later studies confirmed that vimentin expression clearly differentiated ccRCC from chromophobe RCC and the added loss of CD9 expression in ccRCC as another identifying gene marker verified by immunohistochemical staining of patient tissue [18].

Studies from our laboratory have previously identified that an early event in ccRCC is loss of expression of the type III TGF- $\beta$ receptor (T $\beta$ RIII) and that re-expression of T $\beta$ RIII leads to decreased ccRCC cell growth and induction of apoptosis $[19,20]$. We have also identified that the loss of T $\beta$ RIII is due to epigenetic silencing of the transcription factor GATA3, a positive regulator of T $\beta$ RIII expression [21]. Loss of T $\beta$ RIII and later loss of T $\beta$ RII between stage 2 and stage 3 ccRCC identifies that the inability of cells to respond to TGF- $\beta$ signaling is an important event in ccRCC initiation and progression [19]. Both TßRIII and GATA3 are being further investigated as candidate biomarkers for ccRCC as well as potential targets for therapy. Recent gene expression profiling of ccRCC has identified that high expression of cell cycle related genes aurora kinase B (AURKB), cyclin dependant kinase 1 (CDK1) and polo-like kinase 1 (PLK1) are associated with advanced ccRCC and decreased patient survival [22]. Inhibition of PLK1 in tumor bearing mice inhibited tumor growth suggesting PLK1 as a potential therapeutic target in ccRCC patients.

Analysis of gene expression signatures from early stage ccRCC have shed light on pathways that are modulated in early tumorigenesis when compared to matched patient normal renal tissue [23]. Three pathways were identified which are involved with immune activation, downregulation of metabolism and loss of normal renal function. Along with these pathway changes, the transcription factors GATA3, TFCP2L1, TFAP2B and DMRT2, all of which are important for normal renal development, were identified to be down-regulated in these early stage ccRCC tumors. The down-regulation of metabolism and loss of normal renal function were verified by a separate group who also identified upregulation of many signal transduction genes in ccRCC [24].

Genes have further been identified which are differentially expressed in ccRCC patients with relatively non-aggressive disease compared to those with aggressive disease $[25,26]$. In studies by Takahashi et al. ceruloplasmin had the highest increase in expression when compared to normal renal tissue while vascular endothelial growth factor (VEGF) was highly expressed in $96 \%$ of 29 patient ccRCC samples. These studies also identify groups of genes whose up-regulation in ccRCC support favorable outcome, versus another group of genes that when lost in ccRCC are associated with a poorer outcome. Later investigations by Kosari et al. identified a panel of 34 genes that were predictive for the determination of aggressive, non-aggressive and non-neoplastic samples [26]. Both of these studies identify potential biomarkers for disease that can be measured from primary site tumors and might be predictive of tumor aggressiveness and metastatic potential.

\section{Protein markers of ccRCC in tissue}

Immunohistochemical evaluation of tissue samples derived from patients who have undergone nephrectomy have allowed for validation of findings observed in gene array analysis and for the identification of potentially novel prognostic protein biomarkers for tumor recurrence, aggressiveness and patient survival. Along with other factors such as tumor size, stage and nuclear grade, these biomarkers could compliment and assist in determining survival or treatment options available to those patients showing greatest risk for recurrence and metastasis. The use of PAX-8, PAX-2, human kidney injury molecule-1 (hKIM-1), renal cell carcinoma monoclonal antibody (RCCma), $\mathrm{CD} 10$ and hepatocyte nuclear factor-1- $\beta$ as immunohistochemical biomarkers for the diagnosis of metastatic ccRCC have recently been reviewed and therefore will not be discussed within this article [27]. However, these markers have the potential for increased sensitivity and specificity for the diagnosis of metastatic ccRCC.

A number of studies have identified protein biomarkers whose expression analysis could assist with post-operative decisions as to treatment options for ccRCC patients by distinguishing those with higher risk for reoccurrence of disease or metastasis. A number of factors encompassing tumor size, tumor stage, Eastern Cooperative Oncology Group performance status, and the expression of Ki67, EpCAM and p53 have all been identified to be significantly associated with recurrence in ccRCC [28]. Other molecular markers such as the expression in primary ccRCC tumors of the calcium-dependent phospholipid-binding protein annexin II is associated with higher tumor stage and is an independent predictor of metastasis [29]. High levels of plasminogen activator inhibitor-1 expression in ccRCC is associated with high nuclear grade, advanced stage, distant metastatic sites and/or decreased disease-free survival [30]. On the flip side, low tumor expression of the Type II TGF- $\beta$ receptor (T $\beta$ RII) has been associated with a less aggressive tumor phenotype and a better overall cancer-specific survival compared to patients with higher expression levels of T $\beta$ RII [31]. Decreased expression of TIMP3 is observed in $95 \%$ of ccRCC tumors and significantly correlates with decreased expression of T $\beta$ RII [32]. Analysis of patient tumor molecular signatures consisting 
of the expression of Ki-67, p53, VEGFR-1, epithelial VEGFR-1 and epithelial VEGF-D are capable of predicting disease free survival for localized ccRCC after nephrectomy [33].

Molecular signatures have also been utilized for the prediction of disease prognosis and patient survival. One predictive model for survival takes into account metastasis status, tumor stage, Eastern Cooperative Oncology Group performance status, CAIX, p53 and vimentin [34]. The expression of survivin in ccRCC has been identified as an independent predictor of ccRCC progression and cancer specific death [35], while expression of $\mathrm{B} 7-\mathrm{H} 1$ in ccRCC tumors has been associated with rapid cancer progression and accelerated cancer specific mortality [36]. Together, survivin and $\mathrm{B} 7-\mathrm{H} 1$ are collaborative predictors of ccRCC patient survival [37]. Tissue arrays from 150 patients with metastatic ccRCC identified that increased expression of p53, gelsolin and Ki-67 and decreased expression of carbonic anhydrase 9 and 12 correlated with an unfavorable prognosis [38]. Previous studies had already shown a correlation of carbonic anhydrase 9 (CAIX) expression, alone or in combination with $\mathrm{Ki}-67$, as a predictor of patient survival $[39,40]$. Further studies examining CAIX stated that although loss of CAIX was associated with increased risk of ccRCC related death, it could not be classified as an independent marker and that its expression in other extra-renal organs questions its ability to be a prognostic marker or therapeutic target of ccRCC [41]. However, high expression of CAIX in ccRCC and RCC has been shown to predict responsiveness to interleukin 2 therapy [42].

Data from the analysis of grade 2 ccRCC tumors suggest a different role for gelsolin than those seen in the metastatic tumor studies above as in grade 2 tumors, decreased expression of gelsolin along with an increased expression of Ki-67 is suggestive of poor cancer-specific survival [43]. Along with high expression of Ki-67 and p53, the high expression of VEGF and caveolin are associated with decreased patient survival while high expression levels of bcl-2 and cyclin D1 are associated with increased survival. Of these biomarkers, the expressions of p53 and bcl-2 have been identified as individual predictors of disease specific survival [44].

Two studies have identified that the $\mathrm{p} 65 / \mathrm{NF}-\mathrm{\kappa B}$ signaling pathway may be a potential therapeutic target for ccRCC because of its correlation of expression with VEGF and osteopontin (OPN). Dordevic et al. identified that a higher, inhomogeneous expression of VEGF was associated with $\mathrm{p} 65 / \mathrm{NF}-\mathrm{\kappa B}$ activity [45], while further research from members of the same group suggest that $\mathrm{p} 65 / \mathrm{NF}-\kappa \mathrm{B}$ signaling may be involved in OPN-mediated ccRCC progression [46]. As VEGF is an important factor in angiogenesis, a process known to be involved in tumor progression and metastasis, and osteopontin has been identified to play a role in tumorigeneis and metastasis [47], targeting these proteins and the members of the transcription factor family NF- $\kappa B$ could be important therapeutic options for the treatment of ccRCC.

We have recently analyzed over 75 individual ccRCC normaltumor tissue protein lysate pairs by standard proteomic methods. These samples can also be subdivided into four different pathological stages, Stage 1 to Stage 4 . The proteomic analysis of a pooled subset of these samples was done for each of the 4 normal-tumor ccRCC pooled sample pairs ( $\mathrm{n}=5$ from each stage grouping). As shown in Table 1 , select proteins based on our previous studies [23] and other studies described in the preceding paragraphs are provided. Averaged spectral count values for each pool and condition are listed. The enolase overexpression in the tumor samples and lack of aldolase B expression is consistent with other previous reports [27], and data from the Copland laboratory [23]. As highlighted by aldolase B and using the same spectral counting criteria, there are an additional 80 enzymes involved

\begin{tabular}{|c|c|c|c|c|c|c|c|c|}
\hline \multirow{2}{*}{ Protein Name } & \multicolumn{2}{|c|}{ Stage 1 } & \multicolumn{2}{c|}{ Stage 2 } & \multicolumn{2}{c|}{ Stage 3 } & \multicolumn{2}{c|}{ Stage4 } \\
\cline { 2 - 9 } & N & T & N & T & N & T & N & T \\
\hline Aldolase B & 53 & ND & 45 & ND & 85 & ND & 79 & 39 \\
\hline Gamma Enolase & ND & 63 & ND & 12 & ND & 46 & ND & 29 \\
\hline Adipophilin & ND & 63 & ND & 12 & ND & 46 & ND & 29 \\
\hline TGF-beta induced & 23 & 107 & 14 & 12 & 12 & 36 & 11 & 20 \\
\hline Vimentin & 107 & 168 & 60 & 62 & 96 & 189 & 201 & 271 \\
\hline Isocitrate DH & 11 & 3 & 11 & 2 & 11 & ND & 8 & 3 \\
\hline Gelsolin & 11 & 13 & 12 & 2 & 8 & 7 & 8 & 12 \\
\hline Ceruloplasmin & 9 & 10 & 9 & 6 & 3 & 8 & 12 & 16 \\
\hline
\end{tabular}

Table 1: Selected expression of putative ccRCC protein biomarkers in pooled normal $(\mathrm{N})$ and tumor $(\mathrm{T})$ tissues representative of Stage 1-4 cancers Individual renal tissues $(10-15 \mathrm{mg})$ from matched tumor and normal pairs were processed by trifluoroethanol (TFE) solubilization and sonication as adapted from Wang et al. [104]. Following trypsin digestion, the resulting peptides were separated by MudPIT and analyzed for protein identification as described in the legend to Table 2. Results are listed as spectral counts for each indicated protein.

in basic metabolic processes that were at least 2 -fold or greater underexpressed in the tumor tissues, across all four stages. Thirty five of these enzymes are involved in lipid and coenzyme A metabolism (data not shown). Conversely, in addition to gamma-enolase and its expression trend of tumor over-expression, three other enzymes upstream and downstream of enolase were similarly over-expressed: pyruvate kinase M1/M2, 6-phosphofructokinase and ATP citrate synthase. These dramatic changes in metabolic enzyme levels are consistent with the Warburg effect and the transcriptomic data previously reported [23].

\section{Fluid based biomarkers: Serum}

Fluid based biomarkers for detection, stage, progression or regression of disease with available targeted treatment options are attractive due to their ease of acquisition and for ease of follow-up monitoring of disease during subsequent patient checkups. On a more global scale, the identification of fluid based biomarkers could allow for the earlier detection of a number of primary and metastatic growths within the patient [48]. Over the past decade, there have been extensive biomarker discovery efforts using emerging mass spectrometrybased methods that include profiling of low molecular weight serum proteins $[49,50]$ and analysis of post-translational modifications like glycosylation [51]. Once discovered and validated, detection of serum biomarkers is routinely done with automated ELISA formats, the most common example being detection of serum prostate specific antigen for prostate cancers [51]. Mulitplexed immunological assays incorporating bead-based approaches are also being developed [52]. For ccRCC, a number a number of proteins identified to be overexpressed at the protein level in resected patient tissues have also been identified to be elevated in ccRCC patient serum. Notably, elevated levels of VEGF [53] have been identified as has elevated expression of osteopontin [54]. Elevated levels of osteopontin were associated with poor survival of patients and as a potential marker for distant metastasis [54]. Other serum markers of note include: elevated levels of $\mathrm{B} 7 \mathrm{x}$, a protein that inhibits cell-cycle progression, proliferation, and cytokine production of both CD4+ and CD8+ T cells which is elevated in ccRCC patient serum and is associated with advanced stage disease [55]; ceruloplasmin, the major copper carrying blood protein has also been identified to be secreted by ccRCC tumors and elevated levels have been observed in patient serum [56,57]; and significant elevation of TGF- $\beta 1$ has been recorded in plasma from patients with ccRCC [58]. Analysis of soluble B7-H1 in patient sera agreed with findings from IHC studies in that higher expression of this protein in preoperative samples was associated with large tumors, advanced grade and poor patient survival [59]. 


\section{Urine biomarkers}

Urine as a medium for biomarker analysis has a number of advantages over serum including ease of collection, lack of interfering proteins and its molecular activity changes little after sampling [60]. Examination of RCC patient urine utilizing methylation specific PCR techniques to identify promoter hypermethylation of six tumor suppressor genes discovered that hypermethylation of VHL was only found in ccRCC urine samples. Hypermethylation of p14ARF, APC and RASSF1A were more frequent in non-ccRCC samples and none of these genes were methylated in normal patient urine controls [61].

Studies undertaken in breast, bladder and prostate cancers have identified proteins expressed in the urine that correlate with each of these disease states [62,63]. Investigations in RCC have identified two novel urine biomarkers, aquaporin 1 and adipophilin, that are highly expressed in kidney cancers that originate from the proximal tubules (ccRCC and papillary) [64]. Another group has identified several components of the urine that allows for recognition of patients with ccRCC in comparison to healthy volunteer samples [65] with another using three urine specific signals to achieve the same outcome [66]. These three signals showed $100 \%$ sensitivity for stage 1 ccRCC.

\section{Animal models for identification of potential biomarkers}

As early as 1979, the ability of implanted patient tumors in immuno-suppressed mouse models to produce secreted proteins had been observed [67]. In these studies, a number of freshly resected solid human tumors were subcutaneously implanted into female athymic nude mice of the BALB/c background and plasma obtained at the time of serial transplantation. Each of these plasma samples were then tested for the expression of 20 different protein markers. In the case of the ccRCC tumor implants, plasma from both implanted mice expressed human albumin, a1-antitrypsin and transferrin. These studies identify that humanized mouse tumor models have the potential to identify serum soluble biomarkers of disease.

We have recently used proteomic identification techniques along with validation by real-time PCR to identify and validate serum soluble proteins that are secreted into the serum of humanized mouse tumor models in the search of ccRCC specific biomarkers. Fresh, de-identified patient ccRCC tumor tissue along with distant site normal kidney tissue were obtained from Mayo Clinic Florida (with Mayo Clinic Institutional Review Board (IRB) approval), cut into $1 \mathrm{~cm}^{3}$ sections and subcutaneously implanted into female nude mice in accordance with Mayo Clinic Institutional Animal Care and Use Committee (IACUC) and the National Institute of Health Guide for the Care and Use of Laboratory Animals (NIH publications No. 80-23, revised 1996). Less than $10 \%$ of the fresh, transplanted tumor tissues seeded within these investigations. Serum was collected via terminal heart bleeds prior to tumor harvest and subsequent passage.

Serums from these animals were analyzed by commercial serum biomarker and cytokine antibody arrays and mass spectrometrybased protein identification methods, summarized as follows. Use of a commercial antibody array allowed rapid screening of serum obtained from individual explanted mice carrying normal kidney, non-metastatic tumor and metastatic tumor tissues. As shown in Figure 1, the antibody array was effective at identifying potential candidates related to progression to metastatic disease. These include cathespsin B, CA19-9, CA15-3, PAI-1, IL-12 and IL-6. Further analysis using a murine cytokine array panel established that increased IL-12 and IL-6 levels were also detected in pooled metastatic serum. While encouraging and consistent with previous reports about increased IL-12 and IL-6 expression in RCC [68,69], this data highlights one of the major challenges in using proteomics profiling to delineate mouse serum from human explant models. Is the signal detected really specific to mouse or human species? Analysis of serum proteins by standard methods is even more confounding. The high sequence homology of serum proteins in mice and humans makes interpretation of species specific protein level changes difficult to access. As summarized in Table 2, common serum proteins are listed with their comparative levels in pooled serum samples from normal tissue, non-metastatic tumor and tumor tissues determined by spectral counting. The protein names are listed under each sub-group in which the highest level of expression was detected. As would be expected, major serum proteins were detected (albumin and immunoglobulins were excluded), and included many of the potential biomarkers described for ccRCC. Of note is the striking difference in the levels of different complement proteins $(\mathrm{C} 3$, factor $\mathrm{B}$, factor $\mathrm{H}$, factor $\mathrm{I})$ detected in mouse serum from animals implanted with normal renal tissues relative to tumor tissues. The lack of complement protein changes associated with the tumor tissues could lead to different approaches for evaluating and comparing the immune response to ccRCC in humans. Expression of gelsolin and ceruloplasmin as determined by spectral counting were verified by western blotting (Figure $2 \mathrm{a}$ and $2 \mathrm{~b}$ ) confirming loss of gelsolin expression and increased ceruloplasmin expression in serum samples from mice bearing human metastatic ccRCC tissue. Analysis of tissue mRNA expression in a separate patient matched data set was also performed but the results did not correlate with serum protein expression levels (Figure $2 \mathrm{c}$ and $2 \mathrm{~d}$ ). Further analysis of serum samples will require the use of antibodies vetted for species specificity, and more extensive fractionation of the serum prior to MS detection to get into the lower abundance proteins present, potentially focusing on $\mathrm{N}$-glycoproteins for parallel depletion/enrichment of tumor secreted proteins. As this explant model has the potential to provide great utility in testing and evaluating potential ccRCC therapeutics, this baseline type of data is critical in interpreting future results. Being able to identify host murine protein changes in response to human tumor implantation, relative to changes in the secretome of human tumor proteins, could lead to novel serum based biomarker candidates for use in human studies.

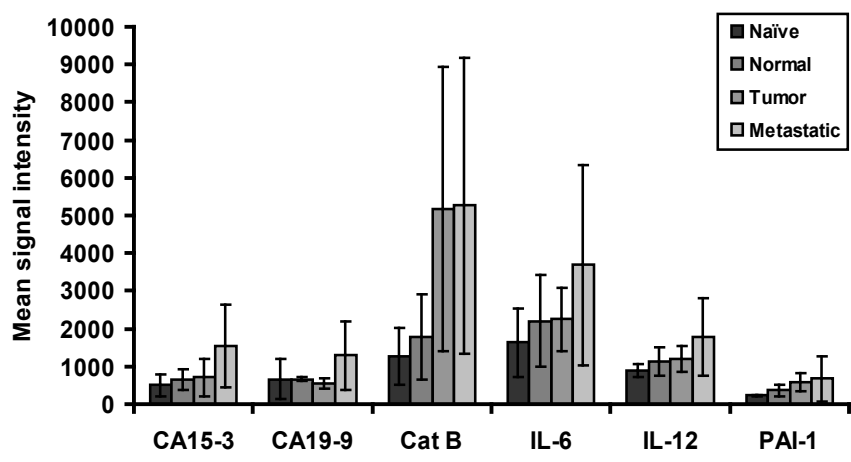

Figure 1: Cancer biomarker antibody array analysis of sera from mouse renal tissue explants. Individual sera from control mice $(n=2)$, normal renal tissue $(n=3)$, non-metastatic tumor $(n=5)$ and metastatic tumor $(n=4)$ were analyzed on a Cancer Biomarker antibody array slide and detected using a SilverQuant detection kit (both from Gentel Biosciences). Intensity values for each of the 42 proteins analyzed per sample were averaged for each sample group. 


\section{MicroRNA biomarkers of ccRCC}

One of the most current forms of molecular characterization of tumors is that of microRNA (miRNA) profiling. miRNAs are naturally occurring, non-coding RNA sequences of 18-25 nucleotides in length that target mRNA to cause its degradation or repression of translation and subsequent decrease in specific protein expression. Investigations have identified that the aberrant expression of miRNAs is involved in the pathogenesis of many different human cancers [70-73]. The recent identification of miRNAs present in human plasma [74-76] and urine [76-79] raises the exciting possibility that circulating miRNA profiles could be used for clarification of tumor histotype, stage and metastatic potential. For instance, studies in breast cancer show significant increases in blood derived miR-34a in patients with advanced stage disease compared to early tumor stages and that the increase of miR$10 \mathrm{~b}, \mathrm{miR}-34 \mathrm{a}$ and miR-155 in serum correlated with the presence of metastases [80].

Studies in renal cancer have identified that the expression of 6 specific miRNAs can distinguish between the 4 subtypes of RCC [81] while others provided miRNA signatures for RCC subtype classification [82]. Expression profiles of miRNA in patient ccRCC tumor samples have identified miRNAs that distinguish all stages of ccRCC from patient matched normal tissue [83-86]. Interestingly from these studies, the majority of these differentially expressed miRNAs were down-regulated in ccRCC when compared to normal control tissues, a phenomenon that has been previously identified in tumor tissue [73]. Furthermore, miRNA signatures for favorable versus unfavorable outcome have been defined for ccRCC with the over-expression of miR-32 being associated with poor outcome [87]. In another study, expression of miR-106b is reported as a potential biomarker for the detection of early metastasis in patients after nephrectomy due to the observed expression levels being lower in patients with metastatic disease compared to patients in disease remission [88].

There is also the potential that targeting the expression of specific miRNAs could lead to potential therapeutics of disease [89]. Therapies to inhibit or reinstate specific miRNAs in cancer could lead to decreases in tumor cell growth as identified in vitro and in vivo [90,91]. In ccRCC, Chow et al. have identified that the miR-71-92 cluster that contains 7 miRNAs, is over-expressed and that individual inhibition of two of these miRNAs (miR-20a and miR-17-5p) in the ACHN cell line inhibited cell proliferation [92]. This group furthered the understanding of miRNA function in ccRCC by predicting that HIFs, mTOR, VEGF and VHL are all potential targets for dysregulated miRNAs [6,92]. Other miRNAs identified to be potential targets for therapy in ccRCC include miR-141 and miR-200c whose expression is down-regulated when compared to normal renal tissue $[84,85]$. Re-expression of these miRNAs in ccRCC cell lines lead to re-expression of E-cadherin [84], suggesting a potential tumor suppressor function. A separate study looking at targets of miR200c observed an anti-correlation with mRNA expression of VEGFA suggesting loss of this miRNA in ccRCC plays a role in increases in VEGFA expression levels [93]. As of the time of publication there is one ongoing clinical trial (Clinical Trial Number: NCT00743054) for the identification of miRNAs in renal cell carcinoma patients, the roles that these miRNAs play on the formation of RCC and discovery of potential biomarkers.

\section{Single Nucleotide Polymorphism (SNP) genotyping and ccRCC}

Recent studies have set forth to identify cytogenetic variants that are capable of predicting patient prognosis in ccRCC patients. Through the use of genome wide single nucleotide polymorph gene arrays, copy number abnormalities and microdeletions have been identified within the genome of these patients. Polymorphs in the promoter of the IL- 4 gene analyzed in a cohort of 80 patients with metastatic RCC have emerged as prognostic factors for survival [94]. Associations with survival have also been observed with SNP polymorphisms in the vascular endothelial growth factor (VEGF) gene [95]. Loss of the p arm of chromosome 9 and chromosome 14q have been frequently observed in ccRCC and when both occur together, have been correlated with a poor prognosis [96]. Singularly, deletion of the 9p chromosome leads to an aggressive phenotype of ccRCC [97] whilst loss of chromosome $14 \mathrm{q}$ is associated with high stage, increased risk of reoccurrence and decreased overall survival [96]. Gain of $8 \mathrm{q}$ is also associated with decreased survival [96] whilst one publication showed that gain of $5 q$ predicts a favorable prognosis in a distinct clinical phenotype of ccRCC [98]. A study carried out in 2010 identified that each subtype of RCC has a distinct cytogenetic profile; $-3 p,+5 q$ and $-8 p$ are only observed in ccRCC, with $-3 p$ and $+5 q$ appearing in all ccRCC tumors independent of grade or stage [99]. This study also identified cytogenetic alterations that take place in early and late stages of ccRCC, alterations that are associated with tumor grade, and alterations associated with patient survival and clinical or pathological factors [99]. As can be seen from these studies, cytogenetic profiling has the potential to determine subtype, stage, grade and patient prognosis in ccRCC.

\section{Conclusions}

As the incidence of ccRCC continues to increase each year, the continued identification of biomarkers for early detection and potential targets for therapeutic intervention are necessary. ccRCC is a fundamentally metabolic disease, and is a clear example of the Warburg effect in tumor metabolism and dramatic alterations in lipid metabolism. There is cumulative genetic, metabolomic, proteomic and lipidomic data that highlight this and point toward multiple targets of individual enzymes and pathways as molecular markers. Integrating and interpreting the breadth of this data remains one of the primary challenges in sorting out the most appropriate candidates for validation as biomarkers and development of diagnostic or prognostic assays. Because ccRCC is so fundamentally a metabolic disorder, sorting out aberrant metabolites that differ from those expected to be present from normal metabolism and diet is an important challenge.

Previous research has identified an abundance of biomarkers for staging of disease, potential for metastasis and determination of patient survival, which along side traditional methods for staging and subtype determination could lead to a deeper understanding of ccRCC and a better prognosis for the patient. However, considerations must be made to tissue acquisition and storage in the continued efforts for biomarker analysis. As reviewed by Napoli and Signoretti, collection and storage, fixation, staining and analysis of patient tissue samples needs to be carefully undertaken so that biological markers of disease are not influenced, degraded or miss validated [100]. Tissue microarray (TMA) results should also be confirmed in stained whole tissue sections verifying that the tissue cores truly represent the overall tumor sample [101]. And finally, it should be noted that as $~ 98 \%$ of human genes are expressed in many different tissues, care must be taken to identify those biomarkers that are truly tissue specific [102] Biological markers identified as potential biomarkers must be sensitive and specific; only found to be present in patients with cancer and never found in those without disease. It may be that a combination of several biomarkers is needed to achieve adequate sensitivity and specificity. These biomarkers identified in multiple systems and validated in large 
Citation: Cooper SJ, Tun HW, Roper SM, Kim Y, Kislinger T, et al. (2012) Current Status of Biomarker Discovery in Human clear Cell Renal Cell Carcinoma. J Mol Biomark Diagn S2:005. doi:10.4172/2155-9929.S2-005

Page 6 of 10

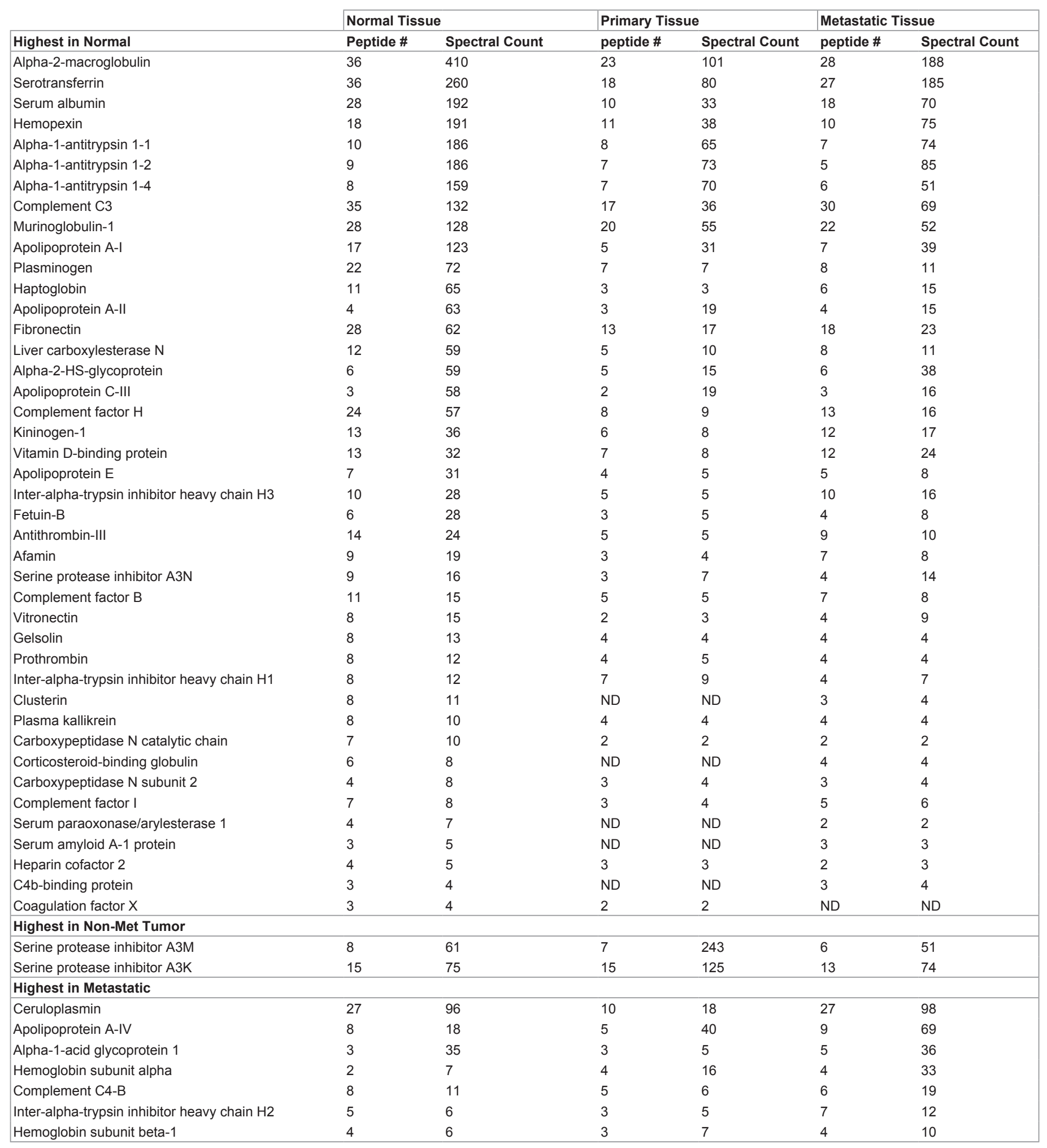

Table 2: Spectral count and peptide number analysis of serum circulating human proteins obtained from pooled humanized ccRCC mouse tumor model systems. Pooled mouse sera ( $n=5 /$ group) from each of the three tissue explant groups were first depleted of albumin and immunoglobulins by a ProteoPrep Al spin column (Sigma-Aldrich). Following overnight trypsin digestion, peptides were analyzed using a 4-cycle automated two dimensional MudPIT separation on an LTQ Orbitrap-XL mass spectrometer as previously described [103]. Protein identifications were accepted if they could be established at greater than $95.0 \%$ probability and contained at least 2 identified peptides per analyzed sample. Raw data was converted to $\mathrm{m} / \mathrm{z}$ XML and searched by SEQUEST against a human or mouse IPI protein sequence database. Results are presented as the most abundantly expressed detected serum proteins in mice implanted with normal kidney tissue, primary ccRCC tumor tissue, or metastatic tumor tissue. Peptide numbers represent the number of individual peptides detected for each protein species, and the spectral count number represents the cumulative number of times a peptide from a given protein was detected across the chromatography run. 
A.

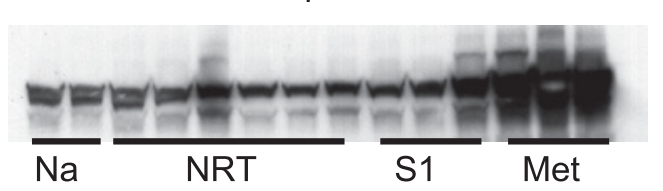

B.

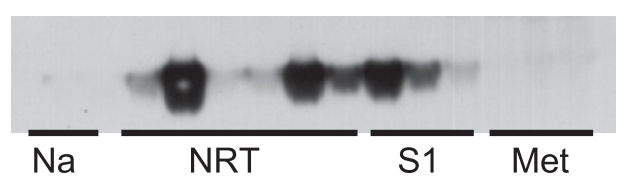

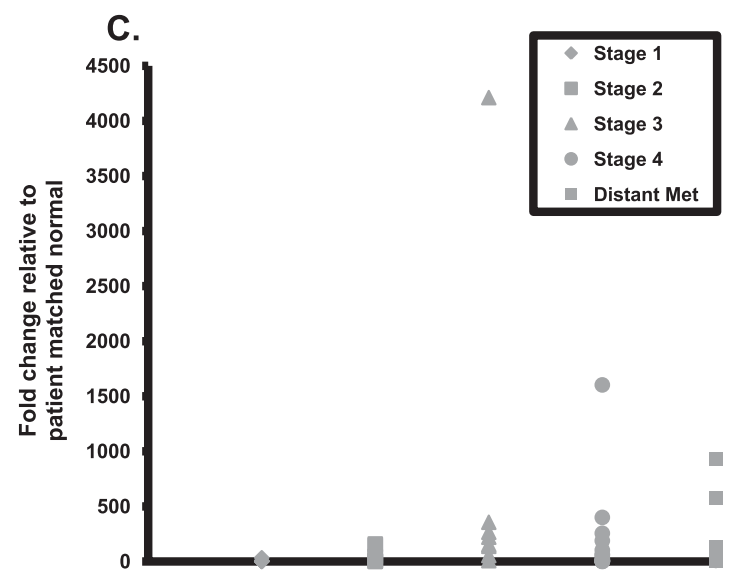

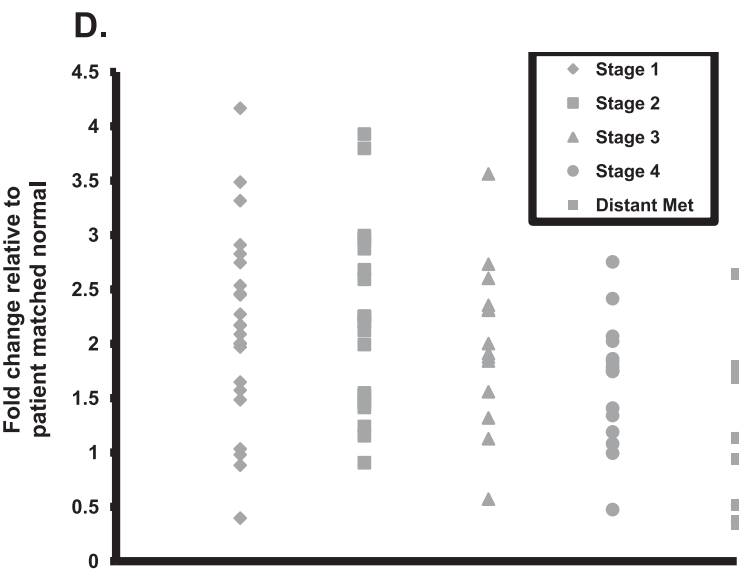

Figure 2: Verification of gelsolin and ceruloplasmin expression levels in the serum of humanized mouse models. As identified in Table 1, protein levels of human gelsolin were highly expressed in serum from mice bearing distant site, normal kidney tissue while human ceruloplasmin expression was highest in the serum of metastatic tumor bearing mice. Serum samples were prepared for western blot analysis and $30 \mu \mathrm{g}$ of fibrin and cell cleared serum loaded per lane. Human specific antibodies confirmed that ceruloplasmin was highly expressed in the serum of metastatic bearing mice (Figure 2a) and gelsolin expression was lost in the same group (Figure $2 \mathrm{~b}$ ). These observations held true when compared to stage 2 and 4 tumors serum samples (data not shown). Na=Naïve; NRT=Normal renal tissue; $\mathrm{S} 1=$ Stage $1 \mathrm{ccRCC}$ tumor tissue; Met=Metastatic site tissue. Analysis of relative mRNA expression levels for ceruloplasmin (Figure $2 \mathrm{c}$ ) and gelsolin (Figure $2 \mathrm{~d}$ ) in patient matched tumor tissues.

patient sample groups have the potential to further our understanding of the underlying biological mechanisms taking place in ccRCC, provide mechanisms for early detection of disease and further assist in identifying molecular pathways for targeted treatment options.

\section{Acknowledgements}

This work was funded in part by $\mathrm{NIH} / \mathrm{NCl}$ grants CA104505 (JAC), R44CA125807 (RRD and JAC), CA104505-05S1 (JAC), Department of Defense grant W81XWH-10-1-0136 (RRD) and a grant from The Mayo Clinic Center for Individualized Medicine (SJC).

\section{References}

1. Jemal A, Siegel R, Ward E, Murray T, Xu J, et al. (2007) Cancer statistics, 2007. CA Cancer J Clin 57: 43-66.

2. Weiss RH, Lin PY (2006) Kidney cancer: identification of novel targets for therapy. Kidney Int 69: 224-232.

3. Pantuck A J, Zisman A, Belldegrun A S (2001) The changing natural history of renal cell carcinoma. J Urol 166: 1611-1623.

4. Wood CG (2007) Multimodal approaches in the management of locally advanced and metastatic renal cell carcinoma: combining surgery and systemic therapies to improve patient outcome. Clin Cancer Res 13: 697s-702s

5. Motzer RJ, Mazumdar M, Bacik J, Berg W, Amsterdam A, et al. (1999) Survival and prognostic stratification of 670 patients with advanced renal cell carcinoma. J Clin Oncol 17: 2530-2540

6. Chow TF, Youssef YM, Lianidou E, Romaschin AD, Honey RJ, et al. (2010) Differential expression profiling of microRNAs and their potential involvement in renal cell carcinoma pathogenesis. Clin Biochem 43: 150-158.

7. (2001) Biomarkers and surrogate endpoints: preferred definitions and conceptual framework. Clin Pharmacol Ther 69: 89-95.

8. Shuin T, Kondo K, Torigoe S, Kishida T, Kubota Y, et al. (1994) Frequent somatic mutations and loss of heterozygosity of the von Hippel-Lindau tumor suppressor gene in primary human renal cell carcinomas. Cancer Res 54 2852-2855.

9. Herman JG, Latif F, Weng Y, Lerman MI, Zbar B, et al. (1994) Silencing of the VHL tumor-suppressor gene by DNA methylation in renal carcinoma. Proc Natl Acad Sci U S A 91: 9700-9704.

10. An J, Rettig MB (2005) Mechanism of von Hippel-Lindau protein-mediated suppression of nuclear factor kappa B activity. Mol Cell Biol 25: 7546-7556.

11. Frew IJ, Krek W (2008) pVHL: a multipurpose adaptor protein. Sci Signal 1 pe30.

12. Banumathy G, Cairns $P(2010)$ Signaling pathways in renal cell carcinoma Cancer Biol Ther 10: 658-664.

13. Yao M, Yoshida M, Kishida T, Nakaigawa N, Baba M, et al. (2002) VHL tumor suppressor gene alterations associated with good prognosis in sporadic clearcell renal carcinoma. J Natl Cancer Inst 94: 1569-1575.

14. Parker AS, Cheville JC, Lohse CM, Igel T, Leibovich BC, et al. (2005) Loss of expression of von Hippel-Lindau tumor suppressor protein associated with improved survival in patients with early-stage clear cell renal cell carcinoma. Urology 65: 1090-1095

15. Schraml P, Struckmann K, Hatz F, Sonnet S, Kully C, et al. (2002) VHL mutations and their correlation with tumour cell proliferation, microvesse density, and patient prognosis in clear cell renal cell carcinoma. J Pathol 196: 186-193.

16. Kim JH, Jung CW, Cho YH, Lee J, Lee SH, et al. (2005) Somatic VHL alteration and its impact on prognosis in patients with clear cell renal cell carcinoma. Oncol Rep 13: 859-864.

17. Young AN, Amin MB, Moreno CS, Lim SD, Cohen C, et al. (2001) Expression profiling of renal epithelial neoplasms: a method for tumor classification and discovery of diagnostic molecular markers. Am J Pathol 158: 1639-1651.

18. Williams A A, Higgins JP, Zhao H, Ljunberg B, Brooks JD (2009) CD 9 and vimentin distinguish clear cell from chromophobe renal cell carcinoma. BMC Clin Pathol 9: 9. 
Citation: Cooper SJ, Tun HW, Roper SM, Kim Y, Kislinger T, et al. (2012) Current Status of Biomarker Discovery in Human clear Cell Renal Cell Carcinoma. J Mol Biomark Diagn S2:005. doi:10.4172/2155-9929.S2-005

19. Copland JA, Luxon BA, Ajani L, Maity T, Campagnaro E, et al. (2003) Genomic profiling identifies alterations in TGFbeta signaling through loss of TGFbeta receptor expression in human renal cell carcinogenesis and progression. Oncogene 22: 8053-8062.

20. Margulis V, Maity T, Zhang XY, Cooper SJ, Copland JA, et al. (2008) Type III transforming growth factor-beta (TGF-beta) receptor mediates apoptosis in renal cell carcinoma independent of the canonical TGF-beta signaling pathway. Clin Cancer Res 14: 5722-5730.

21. Cooper SJ, Zou H, Legrand SN, Marlow LA, von Roemeling CA, et al. (2010) Loss of type III transforming growth factor-beta receptor expression is due to methylation silencing of the transcription factor GATA3 in renal cell carcinoma. Oncogene 29: 2905-2915.

22. Ding Y, Huang D, Zhang Z, Smith J, Petillo D, et al. (2011) Combined Gene Expression Profiling and RNAi Screening in Clear Cell Renal Cell Carcinoma Identify PLK1 and Other Therapeutic Kinase Targets. Cancer Res 71: 52255234.

23. Tun HW, Marlow LA, von Roemeling CA, Cooper SJ, Kreinest $P$, et al. (2010) Pathway signature and cellular differentiation in clear cell renal cell carcinoma. PLoS One 5: e10696.

24. Zhou L, Chen J, Li Z, Li X, Hu X, et al. (2010) Integrated profiling of microRNAs and mRNAs: microRNAs located on Xq27.3 associate with clear cell renal cell carcinoma. PLoS One 5: e15224.

25. Takahashi M, Rhodes DR, Furge KA, Kanayama H, Kagawa S, et al. (2001) Gene expression profiling of clear cell renal cell carcinoma: gene identification and prognostic classification. Proc Natl Acad Sci U S A 98: 9754-9759.

26. Kosari F, Parker AS, Kube DM, Lohse CM, Leibovich BC, et al. (2005) Clear cell renal cell carcinoma: gene expression analyses identify a potential signature for tumor aggressiveness. Clin Cancer Res 11: 5128-5139.

27. Sangoi AR, Karamchandani J, Kim J, Pai RK , JK McKenney (2010) The use of immunohistochemistry in the diagnosis of metastatic clear cell renal cell carcinoma: a review of PAX-8, PAX-2, hKIM-1, RCCma, and CD10. Adv Anat Pathol 17: 377-393.

28. Shvarts O, Seligson D, Lam J, Shi T, Horvath S, et al. (2005) p53 is an independent predictor of tumor recurrence and progression after nephrectomy in patients with localized renal cell carcinoma. J Urol 173: 725-728.

29. OhnoY, Izumi M, Kawamura T, Nishimura T, Mukai K, et al. (2009) Annexin I represents metastatic potential in clear-cell renal cell carcinoma. $\mathrm{Br} \mathrm{J}$ Cancer 101: 287-294.

30. Choi JW, Lee JH, Park HS, Kim YS (2011) PAI-1 expression and its regulation by promoter $4 \mathrm{G} / 5 \mathrm{G}$ polymorphism in clear cell renal cell carcinoma. $\mathrm{J}$ Clin Pathol 64: 893-897.

31. Parker AS, Lohse CM, Wu K, Kreinest P, Copland JA, et al. (2007) Lower expression levels of the transforming growth factor beta receptor type II protein are associated with a less aggressive tumor phenotype and improved survival among patients with clear cell renal cell carcinoma. Hum Pathol 38: 453-461.

32. Masson D, Rioux-Leclercq N, Fergelot P, Jouan F, Mottier S, et al. (2010) Loss of expression of TIMP3 in clear cell renal cell carcinoma. Eur $\mathrm{J}$ Cancer 46: $1430-1437$

33. Klatte T, Seligson DB, LaRochelle J, Shuch B, Said JW, et al. (2009) Molecula signatures of localized clear cell renal cell carcinoma to predict disease-free survival after nephrectomy. Cancer Epidemiol Biomarkers Prev 18: 894-900.

34. Kim HL, Seligson D, Liu X, Janzen N, Bui MH, et al. (2004) Using protein expressions to predict survival in clear cell renal carcinoma. Clin Cancer Res 10: $5464-5471$

35. Parker AS, Kosari F, Lohse CM, Houston Thompson R, Kwon ED, et al. (2006) High expression levels of survivin protein independently predict a poor outcome for patients who undergo surgery for clear cell renal cell carcinoma. Cancer 107: $37-45$.

36. Thompson RH, Kuntz SM, Leibovich BC, Dong H, Lohse CM, et al. (2006) Tumor $\mathrm{B} 7-\mathrm{H} 1$ is associated with poor prognosis in renal cell carcinoma patients with long-term follow-up. Cancer Res 66: 3381-3385.

37. Krambeck AE, Dong H, Thompson RH, Kuntz SM, Lohse CM, et al. (2007) Survivin and b7-h1 are collaborative predictors of survival and represent potential therapeutic targets for patients with renal cell carcinoma. Clin Cancer Res 13: 1749-1756.
38. Kim HL, Seligson D, Liu X, Janzen N, Bui MH, et al. (2005) Using tumor markers to predict the survival of patients with metastatic renal cell carcinoma. J Urol 173: 1496-1501.

39. Bui MH, Visapaa H, Seligson D, Kim H, Han KR, et al. (2004) Prognostic value of carbonic anhydrase IX and KI67 as predictors of survival for renal clear cell carcinoma. J Urol 171: 2461-2466.

40. Bui MH, Seligson D, Han KR, Pantuck AJ, Dorey FJ, et al. (2003) Carbonic anhydrase IX is an independent predictor of survival in advanced renal clear cell carcinoma: implications for prognosis and therapy. Clin Cancer Res 9: 802 811.

41. Leibovich BC, Sheinin Y, Lohse CM, Thompson RH, Cheville JC, et al. (2007) Carbonic anhydrase IX is not an independent predictor of outcome for patients with clear cell renal cell carcinoma. J Clin Oncol 25: 4757-4764.

42. Atkins M, Regan M, McDermott D, Mier J, Stanbridge E, et al. (2005) Carbonic anhydrase IX expression predicts outcome of interleukin 2 therapy for renal cancer. Clin Cancer Res 11: 3714-3721.

43. Visapaa H, Bui M, HuangY, Seligson D, Tsai H, et al. (2003) Correlation of $\mathrm{Ki}-67$ and gelsolin expression to clinical outcome in renal clear cell carcinoma. Urology 61: 845-850

44. Phuoc NB, Ehara H, Gotoh T, Nakano M, Yokoi S, et al. (2007) Immunohistochemical analysis with multiple antibodies in search of prognostic markers for clear cell renal cell carcinoma. Urology 69: 843-848.

45. Djordjevic G, Matusan-llijas K, Sinozic E, Damante G, Fabbro D, et al. (2008) Relationship between vascular endothelial growth factor and nuclear factorkappaB in renal cell tumors. Croat Med J 49: 608-617.

46. Matusan-Ilijas K, Damante G, Fabbro D, Dordevic G, Hadzisejdic I, et al. (2011) Osteopontin expression correlates with nuclear factor-kappaB activation and apoptosis downregulation in clear cell renal cell carcinoma. Pathol Res Pract 207: 104-110.

47. Oates AJ, Barraclough R, Rudland PS (1997) The role of osteopontin in tumorigenesis and metastasis. Invasion Metastasis 17: 1-15.

48. Martin KJ, Fournier MV, Reddy GP, Pardee AB (2010) A need for basic research on fluid-based early detection biomarkers. Cancer Res 70: 5203-5206.

49. Karbassi ID, Nyalwidhe JO, Wilkins CE, Cazares LH, Lance RS, et al. (2009) Proteomic expression profiling and identification of serum proteins using immobilized trypsin beads with MALDI-TOF/TOF. J Proteome Res 8: 41824192.

50. Drake RR, Cazares L, Semmes OJ (2007) Mining the low molecular weight proteome of blood. Proteomics Clin Appl 1: 758-768.

51. Meany DL, Chan DW (2011) Aberrant glycosylation associated with enzymes as cancer biomarkers. Clin Proteomics 8: 7 .

52. Butterfield LH, Potter DM, Kirkwood JM (2011) Multiplex serum biomarke assessments: technical and biostatistical issues. J Transl Med 9: 173.

53. Sato K, Tsuchiya N, Sasaki R, Shimoda N, Satoh S, et al. (1999) Increased serum levels of vascular endothelial growth factor in patients with renal cell carcinoma. Jpn J Cancer Res 90: 874-879.

54. Ramankulov A, Lein M, Kristiansen G, Meyer HA, Loening SA, et al. (2007) Elevated plasma osteopontin as marker for distant metastases and poo survival in patients with renal cell carcinoma. J Cancer Res Clin Oncol 133 643-652.

55. Thompson RH, Zang X, Lohse CM, Leibovich BC, Slovin SF, et al. (2008) Serum-soluble B7x is elevated in renal cell carcinoma patients and is associated with advanced stage. Cancer Res 68: 6054-6058.

56. Saito K, Saito T, Draganac PS, Andrews RB, Lange RD, et al. (1985) Secretion of ceruloplasmin by a human clear cell carcinoma maintained in nude mice. Biochem Med 33: 45-52.

57. Pejovic M, Djordjevic V, Ignjatovic I, Stamenic T, Stefanovic V (1997) Serum levels of some acute phase proteins in kidney and urinary tract urothelia cancers. Int Urol Nephrol 29: 427-432.

58. Junker U, Knoefel B, Nuske K, Rebstock K, Steiner T, et al. (1996) Transforming growth factor beta 1 is significantly elevated in plasma of patients suffering from renal cell carcinoma. Cytokine 8: 794-798. 
Citation: Cooper SJ, Tun HW, Roper SM, Kim Y, Kislinger T, et al. (2012) Current Status of Biomarker Discovery in Human clear Cell Renal Cell Carcinoma. J Mol Biomark Diagn S2:005. doi:10.4172/2155-9929.S2-005

59. Frigola X, Inman BA, Lohse CM, Krco CJ, Cheville JC, et al. (2011) Identification of a soluble form of $\mathrm{B} 7-\mathrm{H} 1$ that retains immunosuppressive activity and is associated with aggressive renal cell carcinoma. Clin Cancer Res 17: 19151923.

60. Schmidt C (2009) Urine biomarkers may someday detect even distant tumors J Natl Cancer Inst 101: 8-10.

61. Battagli C, Uzzo RG, Dulaimi E, Ibanez de Caceres I, Krassenstein R, et al (2003) Promoter hypermethylation of tumor suppressor genes in urine from kidney cancer patients. Cancer Res 63: 8695-8699.

62. Pories SE, Zurakowski D, Roy R, Lamb CC, Raza S, et al. (2008) Urinary metalloproteinases: noninvasive biomarkers for breast cancer risk assessment. Cancer Epidemiol Biomarkers Prev 17: 1034-1042.

63. Roy R, Louis G, Loughlin KR, Wiederschain D, Kilroy SM, et al. (2008) Tumorspecific urinary matrix metalloproteinase fingerprinting: identification of high molecular weight urinary matrix metalloproteinase species. Clin Cancer Res 14: 6610-6617.

64. Morrissey JJ, London AN, Luo J, Kharasch ED (2010) Urinary biomarkers for the early diagnosis of kidney cancer. Mayo Clin Proc 85: 413-421.

65. Kind T, Tolstikov V, Fiehn O, Weiss RH (2007) A comprehensive urinary metabolomic approach for identifying kidney cancerr. Anal Biochem 363: 185195.

66. Bosso N, Chinello C, Picozzi SC, Gianazza E, Mainini V, et al. (2008) Human urine biomarkers of renal cell carcinoma evaluated by ClinProt. Proteomics Clin Appl 2: 1036-1046.

67. Yoshimura S, Tamaoki N, Ueyama Y, Hata J (1978) Plasma protein production by human tumors xenotransplanted in nude mice. Cancer Res 38: 3474-3478.

68. Nong WD S, Fan C, Ouyang J (2007) Relationship of Serum Interleukin-18 and Interleukin-12 Levels with Clinicopathology in Renal Cell Carcinoma. Chinese Journal of Cancer Research 19: 304-308.

69. Blay JY, Negrier S, Combaret V, Attali S, Goillot E, et al. (1992) Serum level of interleukin 6 as a prognosis factor in metastatic renal cell carcinoma. Cancer Res 52: 3317-3322.

70. Esquela-Kerscher A, Slack FJ (2006) Oncomirs - microRNAs with a role in cancer. Nat Rev Cancer 6: 259-269.

71. Garzon R, Calin GA, Croce (2009) MicroRNAs in Cancer. Annu Rev Med 60: 167-179.

72. Volinia S, Calin GA, Liu CG, Ambs S, Cimmino A, et al. (2006) A microRNA expression signature of human solid tumors defines cancer gene targets. Proc Natl Acad Sci U S A 103: 2257-2261.

73. Lu J, Getz G, Miska EA, Alvarez-Saavedra E, Lamb J, et al. (2005) MicroRNA expression profiles classify human cancers. Nature 435: 834-838.

74. Mitchell PS, Parkin RK, Kroh EM, Fritz BR, Wyman SK, et al. (2008) Circulating microRNAs as stable blood-based markers for cancer detection. Proc Nat Acad Sci U S A 105: 10513-10518.

75. Chen X, Ba Y, Ma L, Cai X, Yin Y, et al. (2008) Characterization of microRNAs in serum: a novel class of biomarkers for diagnosis of cancer and other diseases. Cell Res 18: 997-1006.

76. Gilad S, Meiri E, Yogev Y, Benjamin S, Lebanony D, et al. (2008) Serum microRNAs are promising novel biomarkers. PLoS One 3: e3148.

77. Hanke M, Hoefig K, Merz H, Feller AC, Kausch I, et al. (2010) A robus methodology to study urine microRNA as tumor marker: microRNA-126 and microRNA-182 are related to urinary bladder cancer. Urol Oncol 28: 655-661.

78. Wang G, Kwan BC, Lai FM, Chow KM, Kam-Tao Li P, et al. (2010) Expression of microRNAs in the urinary sediment of patients with IgA nephropathy. Dis Markers 28: 79-86.

79. Weber JA, Baxter DH, Zhang S, Huang DY, Huang KH, et al. (2010) The microRNA spectrum in 12 body fluids. Clin Chem 56: 1733-1741.

80. Roth C, Rack B, Muller V, Janni W, Pantel K, et al. (2010) Circulating microRNAs as blood-based markers for patients with primary and metastatic breast cancer. Breast Cancer Res 12: R90.

81. Fridman E, Dotan Z, Barshack I, David MB, Dov A, et al. (2010) Accurate molecular classification of renal tumors using microRNA expression. J Mol Diagn 12: 687-696.
82. Youssef YM, White NM, Grigull J, Krizova A, Samy C, et al. (2011) Accurate molecular classification of kidney cancer subtypes using microRNA signature. Eur Urol 59: 721-730.

83. Juan D, Alexe G, Antes T, Liu H, Madabhushi A, et al. (2010) Identification of a microRNA panel for clear-cell kidney cancer. Urology 75: 835-841.

84. Nakada C, Matsuura K, Tsukamoto Y, Tanigawa M, Yoshimoto T, et al. (2008) Genome-wide microRNA expression profiling in renal cell carcinoma: significant down-regulation of miR-141 and miR-200c. J Pathol 216: 418-427.

85. Yi Z, Fu Y, Zhao S, Zhang X, Ma C (2010) Differential expression of miRNA patterns in renal cell carcinoma and nontumorous tissues. J Cancer Res Clin Oncol 136: 855-862.

86. Huang Y, Dai Y, Yang J, Chen T, Yin Y, et al. (2009) Microarray analysis of microRNA expression in renal clear cell carcinoma. Eur J Surg Oncol 35: 1119 1123.

87. Petillo D, Kort EJ, Anema J, Furge KA, Yang XJ, et al. (2009) MicroRNA profiling of human kidney cancer subtypes. Int J Oncol 35: 109-114.

88. Slaby O, Jancovicova J, Lakomy R, Svoboda M, Poprach A, et al. (2010) Expression of miRNA-106b in conventional renal cell carcinoma is a potentia marker for prediction of early metastasis after nephrectomy. J Exp Clin Cancer Res 29: 90 .

89. Bader AG, Brown D, Winkler M (2010) The promise of microRNA replacement therapy. Cancer Res 70: 7027-7030.

90. Trang P, Medina PP, Wiggins JF, Ruffino L, Kelnar K, et al. (2010) Regression of murine lung tumors by the let-7 microRNA. Oncogene 29: 1580-1587.

91. Wiggins JF, Ruffino L, Kelnar K, Omotola M, Patrawala L, et al. (2010) Development of a lung cancer therapeutic based on the tumor suppressor microRNA-34. Cancer Res 70: 5923-5930.

92. Chow TF, Mankaruos M, Scorilas A, Youssef Y, Girgis A, et al. (2010) The miR-17-92 cluster is over expressed in and has an oncogenic effect on renal cell carcinoma. J Urol 183: 743-751.

93. Liu H, Brannon AR, Reddy AR, Alexe G, Seiler MW, et al. (2010) Identifying mRNA targets of microRNA dysregulated in cancer: with application to clea cell Renal Cell Carcinoma. BMC Syst Biol 4: 51.

94. Kleinrath T, Gassner C, Lackner P, Thurnher M, Ramoner R (2007) Interleukin-4 promoter polymorphisms: a genetic prognostic factor for survival in metastatic renal cell carcinoma. J Clin Oncol 25: 845-851.

95. Kawai Y, Sakano S, Korenaga Y, Eguchi S, Naito K (2007) Associations of single nucleotide polymorphisms in the vascular endothelial growth factor gene with the characteristics and prognosis of renal cell carcinomas. Eur Urol 52 1147-1155.

96. Monzon FA, Alvarez K, Peterson L, Truong L, Amato RJ, et al. (2011) Chromosome $14 \mathrm{q}$ loss defines a molecular subtype of clear-cell renal cell carcinoma associated with poor prognosis. Mod Pathol 24: 1470-1479.

97. La Rochelle J, Klatte T, Dastane A, Rao N, Seligson D, et al. (2010) Chromosome $9 p$ deletions identify an aggressive phenotype of clear cell renal cell carcinoma. Cancer 116: 4696-4702.

98. Gunawan B, Huber W, Holtrup M, Heydebreck A von, Efferth T, et al. (2001) Prognostic impacts of cytogenetic findings in clear cell renal cell carcinoma: gain of $5 q 31$-qter predicts a distinct clinical phenotype with favorable prognosis. Cancer Res 61: 7731-7738.

99. Zhang Z, Wondergem B, Dykema K (2010) A Comprehensive Study of Progressive Cytogenetic Alterations in Clear Cell Renal Cell Carcinoma and a New Model for ccRCC Tumorigenesis and Progression. Adv Bioinformatics 428325

100. Di Napoli A, Signoretti S (2009) Tissue biomarkers in renal cell carcinoma: issues and solutions. Cancer 115: 2290-2297.

101. Eckel-Passow JE, Lohse CM, Sheinin Y, Crispen PL, Krco CJ, et al. (2010) Tissue microarrays: one size does not fit all. Diagn Pathol 5: 48.

102. Vasmatzis G, Klee EW, Kube DM, Therneau TM, Kosari F (2007) Quantitating tissue specificity of human genes to facilitate biomarker discovery. Bioinformatics 23: 1348-1355. 
Citation: Cooper SJ, Tun HW, Roper SM, Kim Y, Kislinger T, et al. (2012) Current Status of Biomarker Discovery in Human clear Cell Renal Cell Carcinoma. J Mol Biomark Diagn S2:005. doi:10.4172/2155-9929.S2-005

Page 10 of 10

103. Drake RR, Elschenbroich S, Lopez-Perez O, Kim Y, Ignatchenko V, et al. (2010) In-depth proteomic analyses of direct expressed prostatic secretions. J Proteome Res 9: 2109-2116.
104.Wang H, Qian WJ, Mottaz HM, Clauss TR, Anderson DJ, et al. (2005) Development and evaluation of a micro- and nanoscale proteomic sample preparation method. J Proteome Res 4: 2397-2403. 